\title{
COKE OVEN WASTEWATER TREATMENT BY TWO ACTIVATED SLUDGE SYSTEMS
}

\author{
C.A. PAPADIMITRIOU ${ }^{1^{*}}$ \\ X. DABOU ${ }^{1}$ \\ P. SAMARAS ${ }^{2}$ \\ G.P. SAKELLAROPOULOS ${ }^{1}$
}

${ }^{1}$ Chemical Process Engineering Research Institute
and Department of Chemical Engineering
Aristotle University of Thessaloniki
PO Box 1520, 54006, Thessaloniki
2 TEl of West Macedonia
Koila, 50100, Kozani

*to whom all correspondence should be addressed \author{
e-mail: papadim@cperi.certh.gr
}

Selected from papers presented in $9^{\text {th }}$ International Conference on Environmental Science and Technology (9CEST2005)

1-3 September 2005, Rhodes island, Greece

\begin{abstract}
In this study two bench scale activated sludge systems were used, a CSTR and an SBR for the treatment of coke - oven wastewater. Both reactors were inoculated with activated sludge from a municipal wastewater treatment plant. At the first stages of operation, reactors were feed by a mixture of municipal wastewater and synthetic wastewater. Full acclimatization of the microorganisms to synthetic wastewater was achieved in 60 days. The operation of the reactors was divided into three distinct periods. The first period was characterized by the treatment of high organic but non-toxic synthetic wastewater. During this period COD and $\mathrm{BOD}_{5}$ removal efficiencies reached 95 and $98 \%$ respectively, in both reactors. Nutrient removal was better in the SBR reactor rather than in the CSTR. In the second period phenol was added in concentrations up to $300 \mathrm{mg} \mathrm{l}^{-1}$. Degradation of phenol started about the $20^{\text {th }}$ day after its introduction to the reactors. In this period no effects of phenol to nutrient removal were observed, whereas the removal efficiency of organic matter in both reactors was slightly decreased. During the third period phenol concentrations of the influent were gradually increased to $1000 \mathrm{mg} \mathrm{I}^{-1}$, while cyanide and thiocyanite were added to the influent composition to concentrations reaching concentrations of 20 and $250 \mathrm{mg} \mathrm{I}^{-1}$ respectively. The composition of the influent of this period was a full assimilation of coke oven wastewater. Introduction of increased phenol concentrations along with cyanide compounds initiated irreversible effects on the activated sludge microfauna of the CSTR causing inherent problems to the treatment process, while SBR showed greater capacity to withstand and degrade toxic compounds. The beginning of this period was characterized by decreased settleability of the suspended solids as well as decrease of organic matter and nutrient removal efficiencies. Monitoring of the effluent characteristics during this period reported over $90 \%$ for organic load, $85 \%$ of nutrient removal and over $90 \%$ of phenol and cyanide removal in SBR, while the removal efficiencies for the CSTR were 75, 65 and 80\% respectively.
\end{abstract}

KEYWORDS: SBR, CSTR, phenol, cyanide, coke oven, activated sludge

\section{INTRODUCTION}

Biological wastewater treatment systems are currently used for the treatment of industrial effluents containing persistent and toxic compounds. However, coke-plant wastewaters contain ammonia, cyanide, thiocyanate, and many toxic organic contaminants such as phenols mono and polycyclic nitrogen containing compounds and PAHs [1,2]. As a result, these compounds limit the application of a biological process for the treatment of such effluents. Historically, the concern on the treatment of coke oven wastewaters started at $70 \mathrm{~s}$ 
in China, where conventional activated sludge units were constructed. However the treated effluent from these units did not comply with the national discharge standards [3]. As a result a considerable amount of research is currently focusing on the study of the most appropriate treatment techniques of the specific wastewaters.

Lim reported that wastewater from coke ovens may be effectively treated by a biological treatment process combined with Fenton's oxidation. However this approach had the disadvantage that the wastewater should be diluted by seawater prior to treatment, in order to reduce the operation costs [4]. However, the increased salinity may adversely affect the processes of sedimentation and dissolution of the activated sludge, and may decrease the survival of the activated sludge microorganisms [5]. Ghose suggested a physicochemical mode of treatment for coke plant effluents by the addition of lime slurry in a secondary sedimentation tank, while efficient ammonia removal might be achieved by synthetic zeolite columns [3]. Furthermore, chemicals have to be added in order to improve sludge dewatering characteristics before vacuum filtration. On the other hand, the combined use of bioferricactivated sludge processes offered enhanced coagulation performance that efficiently removed phenols, cyanide and $\mathrm{BOD}_{5}$ [6]. In this way, activated sludge may be purified through the combined process of bioxidation and bioflocculation; both processes have to be intensified in order to improve the removal efficiency. The most important variable was the quality and physiological status of the microorganisms. Suschka was focusing at the treatment of phenolic coke coking wastes emphasizing the treatment under unstable conditions [1]. The instability was mainly associated with the qualitative characteristics of the effluent. Some other studies were focused on behavioral characteristics and/or biodegradation of specific compounds and mainly with quinine, cyanide and nitrogen containing substances $[2,7]$. Coke plant wastewaters were treated by an anaerobic-anoxicaerobic film system in conjunction to an anoxic- aerobic one in a recent study and it was shown that better nitrogen removal was achieved by the first configuration than the latter one [2]. A two-step biological treatment method has been established consisting of an activated sludge unit followed by a nitrification reactor for the stabilization of the overall biodegradation process [8]. However, there is still no clear evidence about a successful method of treating coke oven effluents, resulting in an efficient removal of both organic and inorganic pollutants. An efficient biological system, which has been used for the treatment of industrial wastewaters, is the Sequential Batch Reactor system (SBR).

The processes and the unit operations taking place in an SBR system are similar to those in a conventional activated sludge. The difference is that all subsequent stages are taking place into a single tank. In addition to the profound advantage of minimization of space requirements, other advantages associated with this configuration are $[9,10]$. As a result, SBR systems are capable of handling various types of wastewaters commonly treated by other techniques. The exploitation of such systems started during the late 50s. Since then, several studies have been performed in order to assess the usefulness and efficiency of such systems. Although Sequencing Batch Reactors were used initially for the removal of COD, the nitrification processes have been studied successfully in these systems. Other studies were presented focusing mainly on SBR efficiency to remove nutrients in order the treated effluent to comply with stringent wastewater standards. Umble and Ketchum used an SBR for biological nutrient removal of municipal wastewater; $\mathrm{BOD}_{5}$, TSS and $\mathrm{NH}_{3}-\mathrm{N}$ removals of 98 , 90 and $95 \%$ respectively were alleviated in a $12 \mathrm{~h}$-cycle [11].In this project, two different systems will be examined for the treatment of coke oven effluents: a conventional biological treatment unit (CSTR) and a Sequential Batch Reactor system (SBR).

\section{MATERIALS AND METHODS}

\section{Bench scale reactors}

Two bench scale activated sludge reactors were used in this work, a continuous system and a Sequential Batch Reactor and the corresponding flow diagrams are shown in Figure 1a and $1 \mathrm{~b}$ respectively. The inoculum of the activated sludge reactors was obtained from the Municipal Wastewater Treatment Plant of Thessaloniki. About 2L of activated sludge were added to the each unit and the systems were fed initially by municipal wastewater for a period of about 3 weeks. Synthetic high strength wastewater was gradually added to the reactor units over an acclimatization period of two months. Synthetic wastewater that was used in this 
work simulated coke oven wastewater. The synthetic wastewater was prepared using the following analytical grade substances: $833 \mathrm{mg} \mathrm{l}^{-1}$ glucose (PANREAC), $2000 \mathrm{mg} \mathrm{l}^{-1}$ sodium acetate (J.T. Baker), $100 \mathrm{mg} \mathrm{l}^{-1} \mathrm{NaCl}$ (J.T. Baker), $50 \mathrm{mg} \mathrm{l}^{-1} \mathrm{CaCl}_{2}{ }^{*} 2 \mathrm{H}_{2} \mathrm{O}$ (J.T. Baker), $20 \mathrm{mg}$ $\mathrm{I}^{-1} \mathrm{KCl}$ (J.T. Baker), $600 \mathrm{mg} \mathrm{l}^{-1} \mathrm{NH}_{4} \mathrm{Cl}$ (J.T. Baker) and $333 \mathrm{mg} \mathrm{l}^{-1} \mathrm{~K}_{2} \mathrm{HPO} 4 * 3 \mathrm{H}_{2} \mathrm{O}$ (J.T. Baker). Additional constituents such as phenol, thiocyanide and cyanide to concentrations up to 800 , 200 and $100 \mathrm{mg} \mathrm{I}^{-1}$ respectively.

\section{Physical and chemical monitoring}

$\mathrm{BOD}_{5}$, Mixed Liquor Suspended Solids (MLSS), Suspended Solids (SS), NO $3, \mathrm{NH}_{4}, \mathrm{NO}_{2}$, COD, phenol and cyanide were measured in accordance to APHA [12].

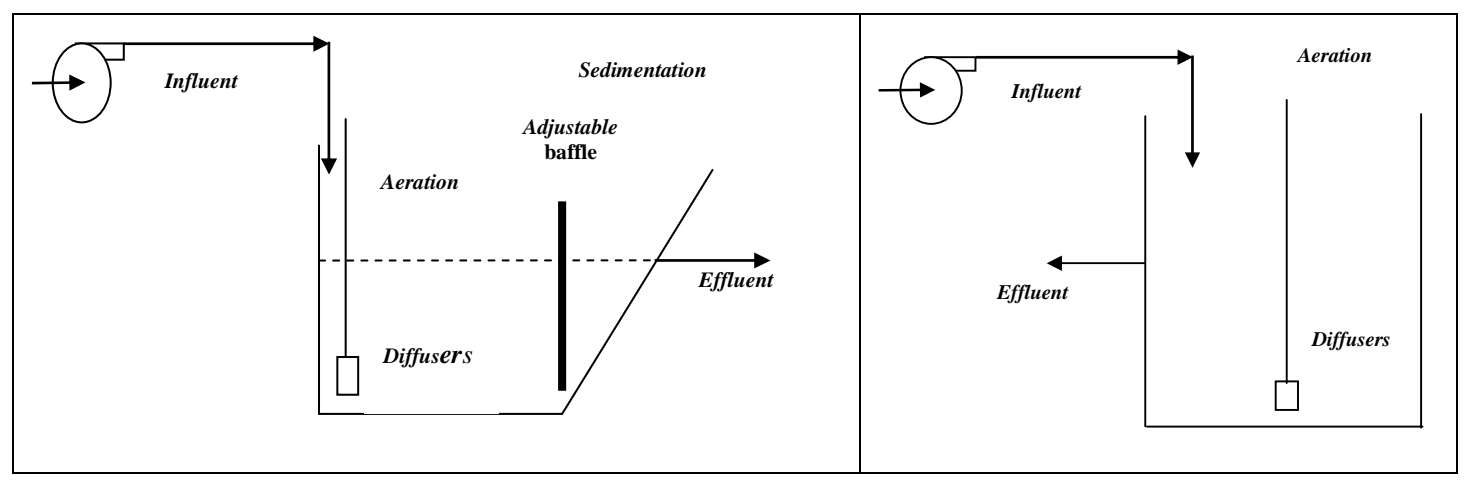

Figure 1. Flow diagrams of the continuous bench scale activated sludge reactor $(A)$ and the sequential batch reactor (B)

\section{RESULTS}

The influent and effluent concentrations of various constituents as a function of operation time, in both reactors, are shown in Figure $1 \mathrm{a}-\mathrm{f}$. Monitoring of the two systems was conducted after the acclimatization of the activated sludge microorganisms to the synthetic coke - oven substrate. Phenol influent content was ranging from 700 to $1200 \mathrm{mg} \mathrm{l}^{-1}$, while the corresponding removal efficiencies were higher than 99\%, in the SBR unit, indicating a complete degradation of influent and effluent phenol values from 1.0 to $4.6 \mathrm{mg} \mathrm{l}^{-1}$. However, the increase of influent phenol content to $800 \mathrm{mg} \mathrm{I}^{-1}$, affected the performance of the CSTR reactor, resulting in the following operation problems:

1. Decrease in the removal capacity of the organic load (BOD, COD).

2. Decrease in nitrification efficiency.

3. Limited phenol degradation, resulting to effluent phenol concentrations ranging from 10 to $60 \mathrm{mg} \mathrm{l}^{-1}$.

4. Decrease in sedimentation capacity.

SBR activated sludge microorganisms proved to be more resistant to the variation of influent phenol content than the corresponding CSTR population, presenting a high recovery rate and a short time for the re-establishment of efficient operation. The addition of phenol might affect the efficiency of both systems for the removal of organic matter. The influent COD content and the corresponding effluent values for both reactors are presented in Figure $2 b$ as $a$ function of operation time, while the corresponding $\mathrm{BOD}_{5}$ values are shown in Figure $2 \mathrm{e}$.

The introduction of high influent phenol concentration did not affect the operation of the SBR reactor, resulting in effluents of high quality: COD concentration varied from 270 to $550 \mathrm{mg} \mathrm{l}^{-1}$ (Fig 2b), corresponding to COD removal efficiencies from 87 to $95 \%$, while BOD $_{5}$ effluent concentration varied from 60 to $152 \mathrm{mg} \mathrm{l}^{-1}$, corresponding to removal efficiencies from 95 to $98 \%$. However, the addition of phenol in the CSTR greatly affected its performance: higher COD values were measured in the CSTR effluent ranging from 295 to $1500 \mathrm{mg} \mathrm{l}^{-1}$, indicating poor COD removal efficiencies of about 67 to 93\%. In addition, $\mathrm{BOD}_{5}$ (Fig 2e) content in the CSTR effluent varied between 150 and $500 \mathrm{mg} \mathrm{l}^{-1}$, resulting in $\mathrm{BOD}_{5}$ removal capacities from 
82,5 to $95 \%$. The reduced effluent quality in the CSTR system was correlated to potential toxic effects of phenol on the certain organisms of the activated sludge microfauna.
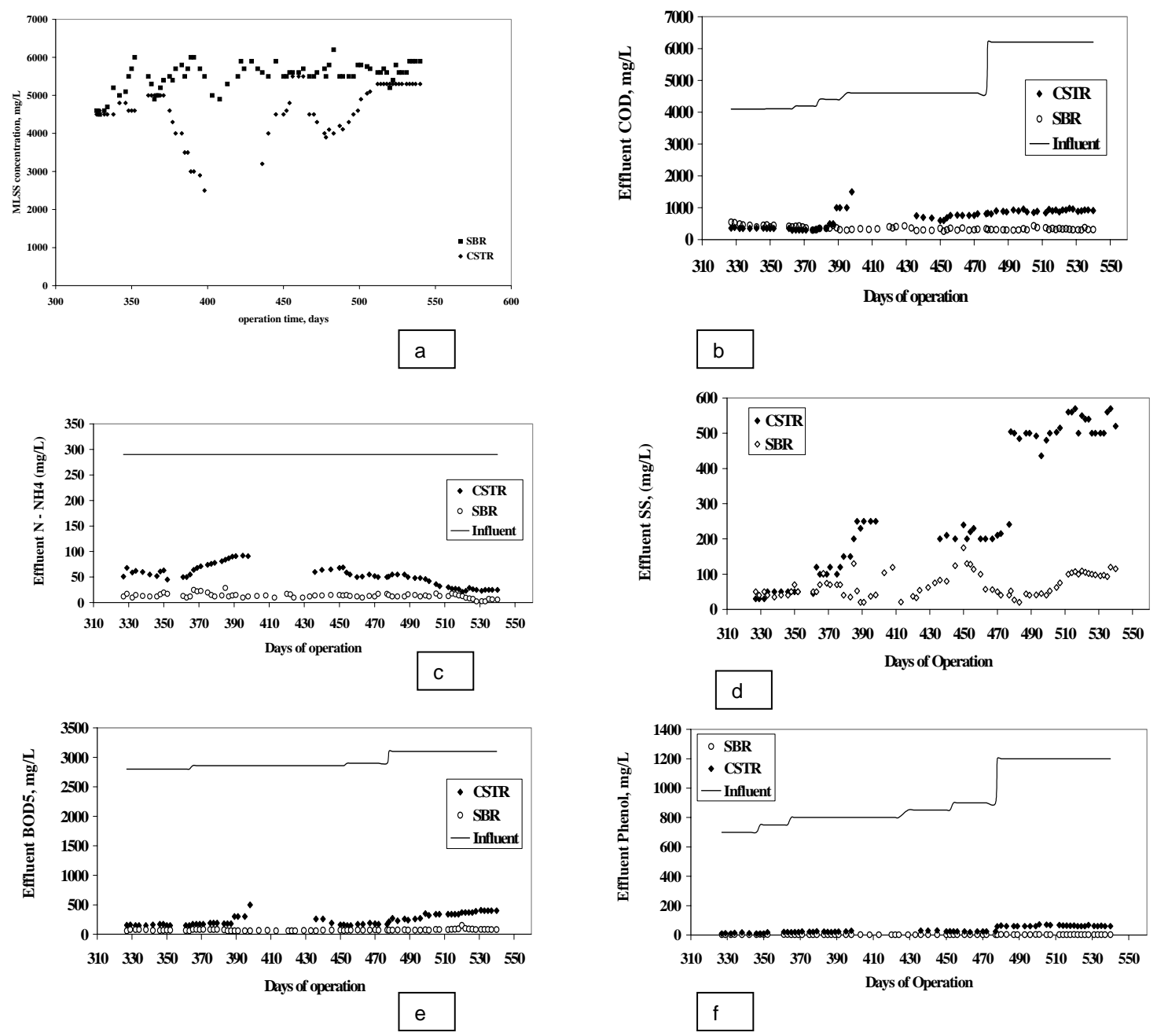

Figure 2 Influent and effluent concentration of a) MLSS, b) COD, c) $\mathrm{N}-\mathrm{NH}_{4}$, d) $\mathrm{SS}$, e) $\mathrm{BOD}_{5}$, f) phenol, as function of operation time, in the bench scale activated sludge reactors

Influent and effluent $\mathrm{NH}_{4}-\mathrm{N}$ concentrations for both reactors are presented in Figure 2c, as a function of operation time. $\mathrm{NH}_{4}-\mathrm{N}$ effluent concentrations in the SBR reactor varied from 2 to $23 \mathrm{mg} \mathrm{l}^{-1}$, corresponding to removal efficiencies from 93 to $99 \%$. Higher effluent values were observed in the CSTR unit, varied from 25 to $91 \mathrm{mg} \mathrm{l}^{-1}$, with corresponding removal efficiencies from 83 to $95 \%$. The nitrification process i.e. the oxidation of ammonia to nitrate, was not affected by the addition of phenol, while at extended operation time, SBR showed a more efficient performance than the CSTR system, resulting in lower ammonia effluent values.

The effluent suspended solids concentration in both systems, as a function of operation time is shown in Figure 2d. Effluent SS content in the CSTR unit exceeded $500 \mathrm{mg} \mathrm{l}^{-1}$ at high influent phenol concentration, while the corresponding values in the SBR system maintained below $100 \mathrm{mg} \mathrm{l}^{-1}$. The variation of influent and effluent cyanide concentration in both bench scale reactors is shown in Figure 3, as a function of the operation time. During this period, influent cyanide concentrations varied from 70 to $270 \mathrm{mg} \mathrm{l}^{-1}$; SBR effluent concentrations ranged between 1,1 and 2,8 $\mathrm{mg} \mathrm{I}^{-1}$ corresponding to about 97 - 99\% removal efficiencies and indicating almost complete removal of cyanide compounds. However, higher effluent 
concentrations were observed in the CSTR unit reaching up to $36 \mathrm{mg} \mathrm{I}^{-1}$, with removal efficiencies from 76 to $98 \%$. Activated sludge microfauna in the SBR unit was satisfactory acclimatized to the addition of cyanides resulting in their enhanced removal. Legislative measures for cyanides are very stringent, setting effluent lower than $1 \mathrm{mg} \mathrm{l}^{-1}$ (Morper and Jell, 2000).

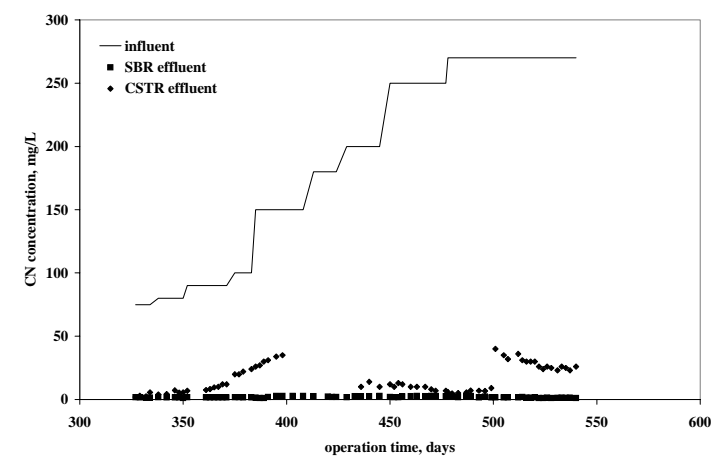

Figure 3 Influent and effluent cyanide concentration as function of operation time, in the bench scale activated sludge reactors

The concentration of microorganisms in the aeration tanks of both systems as a function of operation time is shown in Figure 2a. MLSS content varied between 4600 and $6000 \mathrm{mg} \mathrm{l}^{-1}$ in the SBR system and from 2100 to $5300 \mathrm{mg} \mathrm{l}^{-1}$ in the CSTR system. The addition of phenol and cyanide slightly affected the microorganisms concentration in the SBR system, while a significant effect was observed in the CSTR unit, due to potential toxic effects of these compounds on the activated sludge microfauna. In addition, the CSTR activated sludge microorganisms were more sensitive and did not recover after the toxic shock. Under these conditions, activated sludge presented poor settleability characteristics with a high content of filamentous organisms.

\section{CONCLUSIONS}

In conclusion, the operation of the bench scale activated sludge reactors was studied, under increased concentration of phenol and cyanides. The SBR system showed almost complete phenol degradation for influent concentrations up to $1200 \mathrm{mg} \mathrm{l}^{-1}$, while removal of organic matter in terms of $\mathrm{COD}$ and $\mathrm{BOD}_{5}$ and of ammonia nitrogen indicated no significant inhibition due to the increased phenol loading. The efficient operation of the SBR unit was maintained during cyanide addition, associated to a high cyanide removal rate exceeding $97 \%$. However, phenol addition affected the operation of the CSTR unit resulting to an effluent of low quality with high organic matter content $\left(\mathrm{BOD}_{5}\right.$ higher than $150 \mathrm{mg} \mathrm{l}^{-1}$, COD higher than $\left.300 \mathrm{mg}^{-1}\right)$.

\section{REFERENCES}

1. Suschka J., Morel J., Mierzwinski S. and Janusznek R., (1994) Full-scale treatment of phenolic coke coking wastewater under unsteady conditions, Wat. Sci. Tech., 29, 69-79.

2. Li Y.M, Gu G.W, Zhao J.F, Yu H.Q., Qui Y.L. and Peng Y.Z., (2003) Treatment of coke plant wastewater by biofilm systems for removal of organic compounds and nitrogen, Chemosphere, 52, 997-1005.

3. Ghose M.K., (2002) Complete physicochemical treatment for coke plant effluents, Water Research, 36, 1127-1134.

4. Lim B.R, Hu H.Y., Huang X. and Fujie K., (2002) Effect of seawater on treatment performance and microbial population in a biofilter treating coke-oven wastewater, Process Biochemistry, 38, 943-948.

5. Zhang Z.J., Fukagaewa M., Ukita M. and Nakanishi H., (1995) Treatment of high salinity and high strength organic wastewater consisting of sulfanilamide by two-step contact oxidation process, J. Japan Soci. Wat. Env., 18, 143-169.

6. Littleton X. and Ren Z., (1992) The treatment of wastewater from coke oven and chemical recovery plants by means of bioferric process- an innovative technique, Wat. Sci. Tech., 25(3), 143-156. 
7. Hu H.Y, Fujie K., Tanaka H., Makabe T. and Urano K., (2000) Respiratory quinone profile as a tool for refractory chemical biodegradation study, Wat. Sci. Tech., 35, 103-110, 1997.

8. Morper M. and Jell A., (2000) Two step biological treatment of coke oven wastewater, Linde, Reports on Science and Technology, Achema, special issue, No 62.

9. Subramanian K., Greenfield P.F., Ho K.M., Johns M. and Keller J., (1994) Efficient biological nutrient removal in high strength wastewater using combined anaerobic sequencing batch reactor, Wat. Sci.Tech., 30, 315-324.

10. Kargi F. and Uygur A., (2002) Nutrient removal performance of a sequencing batch reactor as a function of the sludge age, Enzyme Microb. Tech., 31, 842-847.

11. Umble A.K. and Ketchum L.H.Jr., (1997) A strategy for coupling municipal wastewater treatment using the sequence batch reactors with effluent nutrient recovery through aquaculture, Wat. Sci. Tech., 35, 177-184.

12. APHA, (1989) Standard Methods for the Examination of Water and Wastewater, American Public Health Association, American Water Works Association, Water Pollution Control Federation, $17^{\text {th }}$ edition, Washington DC. 